\title{
Comparing tacrolimus ointment and oral cyclosporine in adult patients affected by atopic dermatitis: a randomized study
}

\author{
M. L. Pacor*, G. Di Lorenzo $\dagger$, N. Martinelli*, P. Mansueto $\dagger$, G. B. Rini† and R. Corrocher* \\ *Dipartimento di Medicina Clinica e Sperimentale, Sezione di Medicina Interna, Università degli Studi di Verona, Italy and $\dagger$ Dipartimento di Medicina \\ Clinica e delle Patologie Emergenti, Università degli Studi di Palermo, Italy
}

\begin{abstract}
Summary
Background Atopic dermatitis (AD) is a chronic allergic inflammatory disease, which manifests itself with eczematous skin lesions.

Objective We compared the clinical efficacy of tacrolimus ointment $(0.1 \%)$ given twice a day and oral cyclosporine $(3 \mathrm{mg} / \mathrm{kg})$ given once daily. Rescue medication for itching included cetirizine $10-20 \mathrm{mg}$ (equal to one or two tables).

Methods Thirty patients, aged 13-45 years (mean \pm SD $27.1 \pm 10.9$ ), with a history of moderateto-severe $\mathrm{AD}$ were randomized to treatments, 15 patients for each treatments. Assessment of efficacy was based on SCORAD, on scores of daily itching, erythema, interference with sleep, due to the skin condition and days without use of cetirizine tablets. SCORAD, measured on a scale (0-103), was evaluated before treatment $(0)$ and at 7, 14, 21, 28, 35 and 42 days after treatment. Similarly, the means of daily symptoms, on a scale (0-3), were evaluated before the treatment $(0)$ and at 7, 14, 21, 28,35 and 42 days after treatment; finally, on day without use of cetirizine tablets. The safety of the study treatments was assessed through haematologic, biochemical and urinary testing and on systolic and diastolic blood pressures and heart rate measurements.

Results SCORAD decreased in the two treatment groups 14 days after the beginning of the period study. However, the patients in tacrolimus ointment group reported significantly lower SCORAD than those treated with oral cyclosporine. Overall SCORAD, as assessed by the area under the curve (AUC) $\mathrm{day}_{0-42}$ (score/day), was significantly lower in the tacrolimus ointment group when compared with oral cyclosporine $(P<0.001)$. Similarly, AUC day d $-42_{2}$ (score/day) for itching, erythema and number of nights without interference with the sleep due to skin condition were significantly lower in the group of patients treated with tacrolimus compared with those treated with cyclosporine $(P=0.003,0.005$ and 0.01 , respectively). As regards the use of rescue medication, expressed by median of number of days without use of anti- $\mathrm{H}_{1}$, it was significantly lower in the group treated with tacrolimus (82.5) than in the cyclosporine group $(76.5)(P=0.03)$. There were no appreciable changes in haematological and biochemical indices, in both treatments groups.

Conclusion The results of this comparative study demonstrate that tacrolimus ointment twice daily and cyclosporine administered orally once daily are effective on SCORAD, daily symptoms and anti$\mathrm{H}_{1}$ rescue. When we compared tacrolimus and cyclosporine there was a faster onset of action in the group treated with tacrolimus. The two drugs presented the same safety. However, these data support the preferential use of topical tacrolimus $0.1 \%$ in $\mathrm{AD}$, because cyclosporine has potential side-effects.
\end{abstract}

Keywords atopic dermatitis, cetirizine, cyclosporine, SCORAD, tacrolimus Submitted 25 March 2003; revised 25 July 2003; accepted 17 October 2003

\section{Introduction}

Atopic dermatitis (AD) is a chronic allergic inflammatory disease, which manifests itself with eczematous skin lesions [1]. Recently, an increasing number of patients, particularly adults, had serious problems, with only partial improvement

Correspondence: Prof. Maria Luisa Pacor, Dipartimento di Medicina Clinica e Sperimentale, Sezione di Medicina Interna, Università degli Studi di Verona (Italy), Policlinico GB Rossi, 37134 Verona, Italy.

E-mail: marialuisa.pacor@univr.it or even worsening of lesions, due to resistance to topical steroid therapy. Precise mechanisms underlying AD remain unclear. A biphasic immunological pattern has been suggested, starting with a Th2-type allergic reaction, being allergen-specific, followed by a Th1-type allergic reaction, non-allergen specific. The Th2-type reaction is important in induction of inflammation, whereas Th1-type reaction is responsible for maintenance and aggravation of the inflammation, representing the chronic phase of $\mathrm{AD}[2,3,7]$.

In the majority of cases, in babies, AD ends with a phase of prolonged remission [8]. Cutaneous signs on the hands persist 
during adulthood in $60 \%$ of the cases, with serious subtype of disease. AD continues in adulthood in the $80 \%$ of patients with aggravating factors, such as family history of $\mathrm{AD}$, female subject, an early occurrence of the illness, generalized symptoms in childhood and association with asthma and allergic rhinitis. The persistence of AD in adulthood is only $15 \%$ in absence of these factors [9]. A recent review points out the new insights in physiopathology. The author suggests that the release of mediators (from mast cells, basophils and eosinophils) and of cytokines can be responsible for the thickening and dryness of the skin [9].

However, drugs that suppress both types of allergic reactions would thus be useful for the treatment of $\mathrm{AD}$. Of variable efficiency, systemic corticotherapy is contra-indicated because of the systemic side-effects of a long-term treatment, the rebound phenomenon upon cessation of the treatment and the risk of adrenal insufficiency [8,9]. There is a controversy concerning the use of antihistamines anti- $\mathrm{H}_{1}$, in AD. However, their usefulness against cutaneous itching and their anti-inflammatory properties remain to be established [9-11].

Cyclosporine and tacrolimus, two potent immunosuppressants, with similar mechanisms of action, have an effect on the $\mathrm{T}$ immune response by blocking the activation of $\mathrm{T}$ cells and the antigen presentation by Langerhans cells. Moreover, they inhibit the histamine liberation by the mast cells and the basophils [9-12]. Both cyclosporine and tacrolimus have been used in the treatment of AD [9, 13-15].

No studies had compared tacrolimus administered topically and cyclosporine administered orally in adult patients affected by AD. This study was designed to evaluate the efficacy and the safety of $0.1 \%$ tacrolimus ointment applied to up to $50 \%$ of the total body surface area of adults twice daily and cyclosporine $(3 \mathrm{mg} / \mathrm{kg})$ administered orally once daily, in patients affected by moderate-to-severe AD.

\section{Materials and methods}

Patients

The patients were selected by file of Dipartimento di Medicina Clinica Esperimentale of Verona, Section of Internal Medicine, based on their clinical history of AD and with a confirmed diagnosis of moderate-to-severe AD, according to the criteria of Rajka and Langeland [16]. All patients have been treated with topical corticosteroids and showed partial improvement to the treatment. A total of 30 patients (nine males and 21 females), age ranging from 13 to 45 years, were enrolled. The main exclusion criteria were treatment with systemic corticosteroids, cytotoxic agents or phototherapy within 6 weeks prior to entry, previous treatment with tacrolimus or with cyclosporine, abnormal renal or liver function, hyper-tension and, finally, pregnancy or breastfeeding.

A randomized, double-blind, double dummy, placebocontrolled, parallel-group study was designed. Patients underwent the following treatments:

1. Oral cyclosporine tablets $(3 \mathrm{mg} / \mathrm{kg})$ given once a day and placebo of tacrolimus (ointment without the drug, see below) given twice a day;
2. $0.1 \%$ tacrolimus ointment given twice a day and placebo of cyclosporine.

Rescue medication for itching included cetirizine $10 \mathrm{mg}$ (Zirtec ${ }^{\circledR}$, Torino, Piemonte, Italy). The patients could take from one to two tablets of cetirizine a day, as rescue. No other medication was permitted during the trial.

The pharmacist of the University Hospital of Verona prepared for each patient a specific set of tablets to be used for the study, containing either commercially available tablets of cyclosporine (Sandimmun neoral ${ }^{\circledR}$, Novartis Pharma, Italy) or tablets of placebo. To prepare the $0.1 \%$ ointment, the content of tacrolimus capsules (total $100 \mathrm{mg}$ ) was mixed with $100 \mathrm{~g}$ of hydrophilic petrolatum (white petrolatum composed of $8 \%$ bleached beeswax, 3\% stearyl alcohol and $3 \%$ cholesterol). The placebo ointment of tacrolimus was only made of $100 \mathrm{~g}$ of hydrophilic petrolatum without tacrolimus [17]. All treatments were administered by a person unaware who was participating in the study.

Patients were treated for 42 days after 7 days of run-in. All patients started during the same month. All patients enrolled in the study were sensitized to house dust mites allergens. The patients attended the clinic every 7 days after beginning of treatment and 14 days after ending of the treatment period.

At each visit, SCORAD was assessed and the patients received a daily record diary for AD symptoms (see below).

The local ethics committee of the hospital (Verona, Italy) approved the protocol and patients gave informed written consent to participate in the study.

Severity of the dermatitis was evaluated according to SCORAD [18]. Briefly, for computation of the SCORAD value the percentage of involved body surface is recorded. Regional body surface area tabulation was used to assess the severity of dermatitis over four body areas: head and neck $(\mathrm{H})$, upper extremities (U), trunk (T) and lower extremities (L) were assigned proportionate body surface areas of $10 \%$ (H), 20\% (U), 30\% (T) and 40\% (L), roughly consistent with the 'rule of nines'. Six intensity items (erythema, edema/ papulation, oozing/crusts, excoriations, lichenification and dryness) were then evaluated, ranging 0-3 (absent to severe) and the patients indicate the severity of pruritus and sleep loss $(0-10)$. Total score was thus calculated using the following equation: $\mathrm{SCORAD}=(0.2 \times$ area $)+(3.5 \times[$ eritema + edema $/$ papulation+oozing/crusts + excoriations + lichenification + dry skin]) + subjective score. Index scores of disease severity ranged from 0 to 103 .

\section{Assessment of symptoms}

Patients were instructed to register their daily symptoms on a diary card. AD symptoms included itch intensity, erythema and interference with sleep due to the skin condition. Itch intensity was scored as follows: 0 , no itch; 1 , mild itch; 2, moderate itch; and 3, severe itch. Area of erythema was scored as follows: 0, no erythema; 1, mild erythema; 2, moderate erythema; and 3, severe erythema. Similarly, the patients reported the interference with sleep due to their skin condition on a scale from 0 to 3 : 0 , none; 1 , mild; 2 , moderate; and 3 , severe. 
Fourteen days after the double-blind treatment period, the patients were evaluated by SCORAD and by their spontaneous recording.

\section{Laboratory data}

Blood samples were withdrawn from each patients every 7 days to assess haematologic (haemoglobin, red blood cells, platelets and white blood cells) and biochemical (serum electrolytes [sodium and potassium], renal [creatinine, urea and urinary analysis], hepatic function [alkaline phosphatase, AST, ALT and GGT] and glucose-fasting) testing.

Serum total and specific IgE and blood eosinophil counts were performed after the run-in period and at the end of the period study (after 42 days).

\section{Safety and adverse events}

The safety of the study treatments was assessed through haematologic, biochemical and urinary testing. Systolic and diastolic blood pressures and heart rate were recorded at each visit for each patient. Adverse events were recorded, at each clinic visit, through the spontaneous reports by the patients and through a specific interview or by direct observation of the investigators. The investigator rated the severity of the adverse events using a three-point scale (mild, moderate or severe) and the relationship of each adverse event using the categories unrelated, unlikely, possible, probable and almost certain.

\section{Statistical analysis}

The values of SCORAD and daily symptoms (itching and erythema during the day, interference with sleep due to the skin condition and cetirizine use), after the run-in period, were used to establish baseline values. The same parameters were evaluated at 7, 14, 21, 28, 35 and 42 days after the period study. The serial SCORAD of the 42 days study period were compiled into a graph of disease severity (out to 103) vs. time (days). The area under the curve (AUC) was calculated using the trapezoidal method and denoted as $\mathrm{AUC}_{0-42}$. Such, the measure gives an overall assessment of each patient's SCORAD throughout the 42-day investigation period [19]. Similarly we examined the daily symptoms, recorded on the diary card, using the weekly means. Data were examined using unpaired Student's test. The Kruskal-Wallis test logarithmic transformation was performed on skewed variables such as IgE levels and eosinophils. Finally, the use of rescue medication was expressed as the median of days

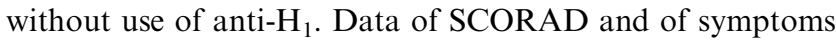
were reported as mean ( \pm standard error of the mean) and as mean difference ( $95 \%$ confidence interval) between the means of the individual scores of the treatments, recorded every 7 days. A value of $P<0.05$ was considered significant.

\section{Results}

All the patients concluded the entire study, including the follow-up period. The baseline characteristics of the patients were reported in Table 1. There were no significant differences between any variable.

\section{SCORAD}

SCORAD was evaluated every 7 days and each time point is illustrated in Fig. 1 and in Table 2. SCORAD decreased in the two treatment groups 14 days after the beginning of the period study. However, the patients in the tacrolimus ointment group reported significantly lower SCORAD than those treated with oral cyclosporine. The difference (mean, $95 \% \mathrm{CI}$ ) between the means of the individual scores of the

Table 1. Patients characteristics

\begin{tabular}{|c|c|c|c|}
\hline & Tacrolimus & Cyclosporine & $P$ \\
\hline$N \dagger$ patients & 15 & 15 & \\
\hline $\mathrm{M} / \mathrm{F}$ ratio & $5 / 10$ & $4 / 11$ & NS \\
\hline Age years $\pm S D$ & $27.1 \pm 10.9$ & $26.6 \pm 10.4$ & NS \\
\hline Height $(\mathrm{cm}) \pm \mathrm{SD}$ & $160 \pm 8.2$ & $165 \pm 7.1$ & NS \\
\hline Weight $(\mathrm{kg}) \pm \mathrm{SD}$ & $58.5 \pm 6.3$ & $56.4 \pm 5.8$ & NS \\
\hline \multicolumn{4}{|l|}{ Median time since diagnosis } \\
\hline of $A D$ (years) & 19 & 15 & NS \\
\hline Body surface area \pm SD & $66.0 \pm 13.5$ & $71.0 \pm 13.7$ & NS \\
\hline Head and neck $(\%)^{\star}$ & 100 & 100 & NS \\
\hline Upper extremities (\%)* & 90 & 70 & NS \\
\hline Trunk $(\%)^{\star}$ & 60 & 50 & NS \\
\hline Lower extremities (\%)* & 50 & 80 & NS \\
\hline SCORAD (mean \pm SEM) & $69.0 \pm 3.9$ & $73.7 \pm 3.5$ & NS \\
\hline Atopy (\%) & 100 & 100 & NS \\
\hline Sensitization to pollen $(\%) \dagger$ & 0 & 0 & NS \\
\hline \multicolumn{4}{|l|}{ Sensitization to indoor } \\
\hline allergens $(\%) \dagger$ & 100 & 100 & NS \\
\hline Asthma $(\%) \dagger$ & 100 & 100 & NS \\
\hline Rhinitis $(\%) \dagger$ & 100 & 100 & NS \\
\hline Conjunctivitis (\%)† & 100 & 100 & NS \\
\hline Serum total $\lg E(k U / L)$ & 1603.1 & 3232.4 & NS \\
\hline \multicolumn{4}{|l|}{ Blood eosinophil counts } \\
\hline$\left(\times 10^{-3} \mu \mathrm{L}\right)$ & 0.18 & 0.16 & NS \\
\hline
\end{tabular}

*Percentage of patients that presented the body area interested by $A D$. $\dagger$ Percentage of patients.

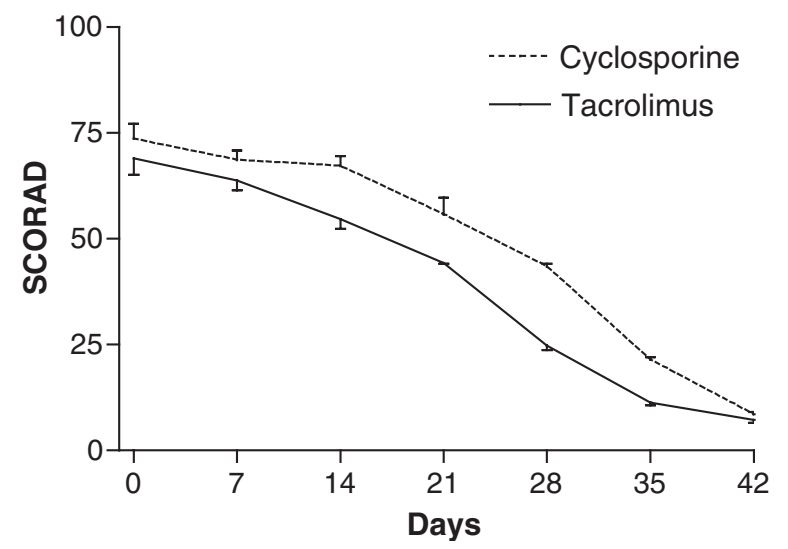

Fig. 1. Graph to show mean (SEM) SCORAD (out to 103) vs. time (days) for patients after treatment with tacrolimus ointment $(0.1 \%)$ and oral cyclosporine $(3 \mathrm{mg} / \mathrm{kg})$. 
Table 2. Summary of SCORAD (out to 103) recording during the investigation period

\begin{tabular}{|c|c|c|c|c|c|}
\hline SCORAD (out of 103) & Tacrolimus & Cyclosporine & Mean difference & $95 \% \mathrm{Cl}$ & $P$-value \\
\hline After run-in* & $69.0(3.9)$ & $73.7(3.5)$ & -4.7 & $(-10.8$ to 1.4$)$ & 0.1 \\
\hline 7 days after treatment ${ }^{*}$ & $63.8(2.4)$ & $68.7(2.2)$ & -4.9 & $(-11.0$ to 1.2$)$ & 0.1 \\
\hline 14 days after treatment ${ }^{*}$ & $54.7(2.3)$ & $67.3(2.3)$ & -12.6 & $(-18.7$ to -6.4$)$ & $<0.001$ \\
\hline 21 days after treatment ${ }^{*}$ & $44.3(0.2)$ & $55.9(3.7)$ & -11.6 & $(-17.7$ to -5.4$)$ & $<0.001$ \\
\hline 28 days after treatment ${ }^{*}$ & $24.8(1.1)$ & $43.5(0.4)$ & -18.7 & $(-24.8$ to 12.5$)$ & 0.001 \\
\hline 35 days after treatment ${ }^{\star}$ & $11.4(0.6)$ & $21.5(1.58)$ & -10.1 & $(-16.2$ to 3.9$)$ & 0.001 \\
\hline 42 days after treatment ${ }^{*}$ & $7.3(0.7)$ & $8.6(0.54)$ & -1.3 & $(-7.4$ to 4.8$)$ & 0.6 \\
\hline Overall SCORAD-AUC $0-42$ (score/days) & $2052.2(69.0)$ & $1660.0(110.2)$ & -392.2 & $(-554.7$ to -229.6$)$ & $<0.001$ \\
\hline
\end{tabular}

${ }^{\star}$ Expressed as mean \pm SEM.

(a)

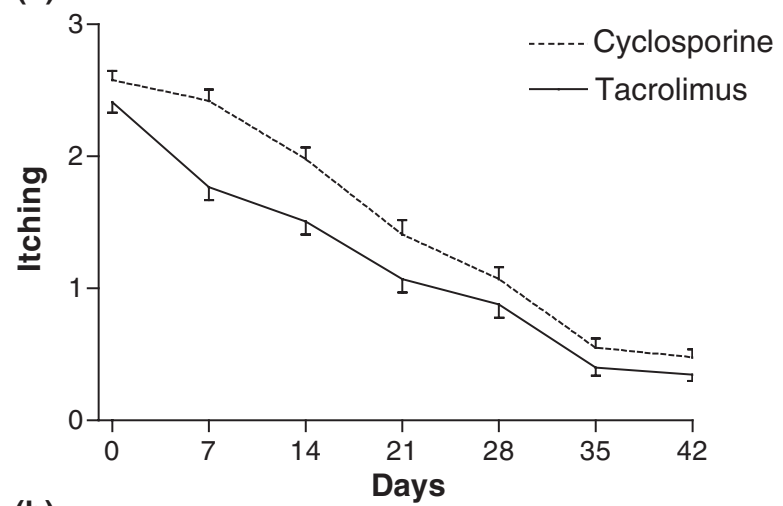

(b)

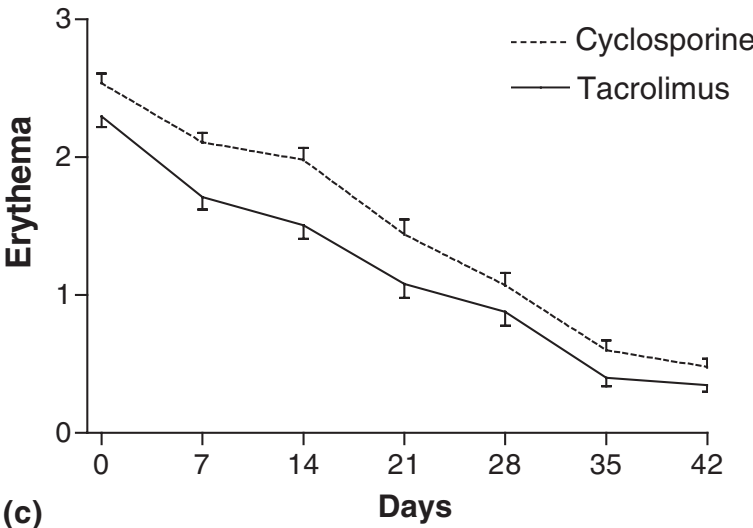

(c)

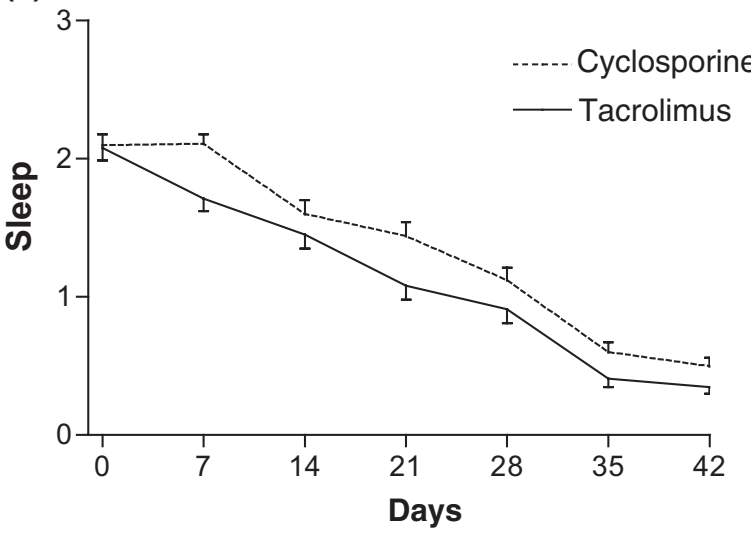

Fig. 2. $(a-c)$ Graphs to show means (SEM) itching, erythema and number of nights without interference with the sleep due to skin condition (out to 3 ) vs. time (days) for patients after treatment with tacrolimus ointment $(0.1 \%)$ and oral cyclosporine $(3 \mathrm{mg} / \mathrm{kg})$. treatments, recorded every 7 days, was: after 14 days, -12.6 ( -18.7 to -6.4$)$; after 21 days, $-11.6(-17.7$ to -5.4$)$; after 28 days, -18.7 ( -4.8 to -12.5$)$; and after 35 days, -10.1 ( -16.2 to -3.9$)$. By contrast, after 42 days the mean of SCORAD was not significantly different: -1.3 ( -7.4 to 4.8 ). Overall SCORAD, as assessed by the $\mathrm{AUC}_{0-42}$, was significantly lower in the tacrolimus ointment group when compared with oral cyclosporine $(P<0.001)$. At the follow-up visit, no changes were detected.

\section{Daily symptoms}

Similarly, $\mathrm{AUC}_{0-42}$ for itching, erythema and number of nights without interference with the sleep due to skin condition were significantly lower in the group of patients treated with tacrolimus compared with those treated with cyclosporine ( $P=0.003,0.005$ and 0.01 , respectively) (Figs 2a-c, Table 3).

\section{Use of rescue medication}

Regarding the use of rescue medication, expressed by median of the number of days without use of anti- $\mathrm{H}_{1}$, it was significantly lower in the group treated with tacrolimus (82.5) than in the cyclosporine group (76.5) $(P=0.03)$.

\section{Serum total IgE and blood eosinophil counts}

Serum total IgE and blood eosinophil counts after the period treatment, both in tacrolimus group and in cyclosporine group, presented a reduction. As regards serum total IgE, the geometric means in cyclosporine group were $1603.1 \mathrm{kU} / \mathrm{L}$ before treatment and $1069.2 \mathrm{kU} / \mathrm{L}$ after treatment $(P=0.7)$. In the tacrolimus group, the geometric means were $3232.4 \mathrm{kU} / \mathrm{L}$ before treatment and $2399.1 \mathrm{kU} / \mathrm{L}$ after treatment $(P=0.6)$. No difference was found between the two groups before $(P=0.8)$ and after treatment $(P=0.7)$. As regards blood eosinophil counts, the geometric means in cyclosporine group were $0.18 \times 10^{-3} \mu \mathrm{L}$ before treatment and $0.08 \times 10^{-3} \mu \mathrm{L}$ after treatment $(P=0.04)$. In tacrolimus group, the geometric means were $0.16 \times 10^{-3} \mu \mathrm{L}$ before treatment and $0.09 \times 10^{-3} \mu \mathrm{L}$ after treatment $(P=0.06)$. No differences were found between the two groups before $(P=0.9)$ and after treatment $(P=0.9)($ Table 4$)$. 
Table 3. Summary of efficacy parameters recording during the investigation period: itching, erythema and interference with sleep due to skin condition

\begin{tabular}{|c|c|c|c|c|c|}
\hline & Tacrolimus & Cyclosporine & Mean difference & $95 \% \mathrm{Cl}$ & $P$-value \\
\hline \multicolumn{6}{|l|}{ Itching (out of 3 ) } \\
\hline After run-in* & $2.41(0.08)$ & $2.58(0.07)$ & -0.17 & $(-0.42$ to 0.08$)$ & 0.1 \\
\hline 7 days after treatment ${ }^{\star}$ & $1.77(0.10)$ & $2.42(0.09)$ & -0.65 & $(-0.91$ to -0.40$)$ & $<0.001$ \\
\hline 14 days after treatment ${ }^{\star}$ & $1.51(0.11)$ & $1.98(0.09)$ & -0.47 & $(-0.72$ to -0.21$)$ & $<0.001$ \\
\hline 21 days after treatment ${ }^{\star}$ & $1.07(0.10)$ & $1.41(0.11)$ & -0.12 & $(-0.59$ to -0.09$)$ & 0.008 \\
\hline 28 days after treatment ${ }^{\star}$ & $0.88(0.10)$ & $1.07(0.09)$ & -0.12 & $(-0.43$ to 0.06$)$ & 0.1 \\
\hline 35 days after treatment ${ }^{\star}$ & $0.40(0.06)$ & $0.55(0.07)$ & -0.15 & $(-0.41$ to 0.09$)$ & 0.1 \\
\hline 42 days after treatment ${ }^{\star}$ & $0.35(0.05)$ & $0.48(0.06)$ & -0.12 & $(-0.67$ to 0.17$)$ & 0.1 \\
\hline Overall itching-AUC $\mathrm{A}_{42}$ (score/days) & $42.9(2.92)$ & $56.6(2.87)$ & -13.7 & $(-22.3$ to -5.07$)$ & 0.003 \\
\hline \multicolumn{6}{|l|}{ Erythema (out of 3 ) } \\
\hline After run-in* & $2.37(0.07)$ & $2.54(0.07)$ & -0.17 & $(-0.42$ to 0.07$)$ & 0.1 \\
\hline 7 days after treatment ${ }^{\star}$ & $1.71(0.09)$ & $2.11(0.07)$ & -0.40 & $(-0.64$ to -0.15$)$ & 0.002 \\
\hline 14 days after treatment ${ }^{\star}$ & $1.51(0.11)$ & $1.98(0.09)$ & -0.47 & $(-0.72$ to -0.22$)$ & $<0.001$ \\
\hline 21 days after treatment ${ }^{\star}$ & $1.08(0.10)$ & $1.44(0.11)$ & -0.35 & $(-0.60$ to -0.10$)$ & 0.008 \\
\hline 28 days after treatment ${ }^{\star}$ & $0.89(0.10)$ & $1.07(0.09)$ & -0.18 & $(-0.43$ to 0.06$)$ & 0.1 \\
\hline 35 days after treatment ${ }^{*}$ & $0.41(0.06)$ & $0.60(0.08)$ & -0.18 & $(-0.43$ to 0.06$)$ & 0.1 \\
\hline 42 days after treatment ${ }^{\star}$ & $0.36(0.06)$ & $0.49(0.06)$ & -0.12 & $(-0.37$ to 0.12$)$ & 0.1 \\
\hline Overall itching-AUC $\mathrm{A}_{0-42}$ (score/days) & $42.6(3.00)$ & $54.8(2.34)$ & -12.2 & $(-20.2$ to -4.16$)$ & 0.005 \\
\hline \multicolumn{6}{|l|}{ Interference with sleep due to skin condition (out of 3) } \\
\hline After run-in* & $2.08(0.09)$ & $2.10(0.08)$ & -0.01 & $(-0.26$ to 0.23$)$ & 0.9 \\
\hline 7 days after treatment ${ }^{\star}$ & $1.71(0.09)$ & $2.11(0.07)$ & -0.40 & $(-0.65$ to -0.14$)$ & 0.002 \\
\hline 14 days after treatment ${ }^{\star}$ & $1.45(0.11)$ & $1.60(0.10)$ & -0.14 & $(-0.39$ to 0.11$)$ & 0.2 \\
\hline 21 days after treatment ${ }^{\star}$ & $1.09(0.10)$ & $1.44(0.11)$ & -0.35 & $(-0.61$ to -0.10$)$ & 0.006 \\
\hline 28 days after treatment ${ }^{\star}$ & $0.91(0.10)$ & $1.12(0.09)$ & -0.21 & $(-0.46$ to 0.03$)$ & 0.09 \\
\hline 35 days after treatment ${ }^{*}$ & $0.41(0.06)$ & $0.60(0.07)$ & -0.18 & $(-0.43$ to 0.06$)$ & 0.1 \\
\hline 42 days after treatment ${ }^{\star}$ & $0.35(0.05)$ & $0.50(0.06)$ & -0.14 & $(-0.43$ to 0.1$)$ & 0.1 \\
\hline Overall interference with sleep-AUC $\mathrm{A}_{0-42}$ (score/days) & $42.2(3.17)$ & $52.4(2.37)$ & -10.1 & $(-18.4$ to -1.81$)$ & 0.01 \\
\hline
\end{tabular}

${ }^{\star}$ Expressed as mean \pm SEM.

Table 4. Geometric means of serum total $\operatorname{lgE}(\mathrm{kU} / \mathrm{L})$ and blood eosinophil counts $\left(\times 10^{-3} \mu \mathrm{L}\right)$ obtained in the two treatment groups

\begin{tabular}{|c|c|c|c|c|}
\hline & \multicolumn{2}{|c|}{ Serum total $\lg E(k U / L)$} & \multicolumn{2}{|c|}{$\begin{array}{l}\text { Blood eosinophil } \\
\text { counts } \times 10^{-3} \mu \mathrm{L}\end{array}$} \\
\hline & $\begin{array}{l}\text { Before } \\
\text { treatment }\end{array}$ & $\begin{array}{l}\text { After } \\
\text { treatment }\end{array}$ & $\begin{array}{l}\text { Before } \\
\text { treatment }\end{array}$ & $\begin{array}{l}\text { After } \\
\text { treatment }\end{array}$ \\
\hline Cyclosporine & 1603.1 & 1069.2 & $0.18^{\star}$ & 0.08 \\
\hline Tacrolimus & 3232.4 & 2399.1 & 0.16 & 0.09 \\
\hline
\end{tabular}

No differences between the groups before and after period of treatment. *Comparing blood eosinophil counts in the cyclosporine group before and after treatment period, $P=0.04$.

\section{Safety and adverse events}

There were no appreciable changes in the haematological and biochemical indices. Serum creatinine was higher in the group treated with cyclosporine after the period of the study, but all values were below the upper limit of normal $(0.8-1.6 \mathrm{mg} / \mathrm{dL})$. No clinically significant changes were noted, for either treatment, in systolic and diastolic blood pressures and heart rate. During the 6-week treatment period, the number of patients reporting adverse events was equal in the two treatment groups (four in the cyclosporine A group and four in the tacrolimus group, respectively). The events characterized by the investigator were mild. The patients in the tacrolimus group reported the sensation of skin burning and the patients in the cyclosporine A group gastric irritation (one patient) and headache (three patients). During the followup period, no $\mathrm{AD}$ exacerbation was observed in the two groups.

\section{Discussion}

AD is a chronic, relapsing, highly pruritic, inflammatory skin disease. Eczema is a chronic inflammation of the skin with a majority of activated $\mathrm{T}$ lymphocytes. Controlling eczema leads to relief not only of the skin inflammation but also of itching.

Schematically, the therapeutical approach required for a successful treatment include: (i) identification and avoidance of the immunologic trigger factors (i.e. allergens, infections, irritants, psychogenic factor); (ii) reduction of the inflammatory cell infiltration in the dermis; and (iii) blockade of the effect of the cytokines and mediators released by the inflammatory cells [9].

As for the available pharmacological options for AD, these are directed at hydrating the skin, reducing inflammation, and relieving symptoms such as pruritus and sleep disturbance. Depending on its severity, AD is usually managed with the liberal use of emollients, topical corticosteroids, antihistamines and antibiotics [20]. 
For patients with a long history of disease, an extensive body surface area involvement, or the presence of facial lesions, the therapeutical options are more limited. In such cases, the use of mild-to-high potency topical steroids are not recommended for long-term use or use on the skin face, neck and intertriginous areas because of the potential manifestation of skin atrophy and/or other side-effects [21]. The longterm use of oral corticosteroids may also lead to adverse effects.

A possible therapeutic option in long-standing disease is the immunomodulators, that is, cyclosporine and tacrolimus [22]. Oral cyclosporine has been reported to be effective for AD, but the cost of treatment and the range of potential long-term side-effects may be even more limiting.

In view of the much more favourable relation between therapeutic and adverse effects, the topical use of tacrolimus will probably increase over the next several years. This drug may represent an alternative to glucocorticoids in the treatment of chronic inflammatory skin diseases, especially for patients who have long-standing AD [23-26] and extensive body surface area involvement, or facial lesions. Both case reports and large, multi-centre, randomized, controlled, double-blind clinical trials have shown the efficacy and safety of tacrolimus. A lack of epidermal atrophy and striae distensae, both potential side-effects of topical glucocorticoid therapy, has been demonstrated for tacrolimus [26].

The results of our comparative study demonstrate that tacrolimus ointment given twice daily and cyclosporine administered orally once daily are effective on SCORAD, on daily symptoms and on anti- $\mathrm{H}_{1}$ rescue. When we compared tacrolimus and cyclosporine there was a faster onset of action in the group treated with tacrolimus. In addition, tacrolimus provided better symptoms control than cyclosporine. This superior efficacy is reflected in the overall SCORED $\left(\mathrm{AUC}_{0-42}\right)$ and also in the symptom score reported during the first 14 days after the beginning of the treatment. At the dose used in the study, cyclosporine presented the same safety of tacrolimus.

However, these data support the preferential use of topical tacrolimus in AD, because cyclosporine has potential sideeffects. No data suggest clinically relevant long-term sideeffects using tacrolimus. Nevertheless, the risk of these potential side-effects such as increased carcinogenesis and especially photocarcinogenesis should be monitored carefully.

\section{Acknowledgements}

This study was supported by grants from Ministero Italiano Università e Ricerca (MIUR) (fondi ex60\%) to Gabriele Di Lorenzo, Maria Luisa Pacor and received no support from the pharmaceutical industry. Statistical advice was kindly provided by Full Professor Antonio Motisi (Dipartimento di Coltivazioni Arboree, University of Palermo).

\section{References}

1 Mihm MC Jr, Soter NA, Dvorak HF, Austen KF. The structure and morphology of normal and atopic eczema. J Invest Dermatol 1976; 67:305-12.
2 Kapsenberg ML, Wierenga EA, Bos JD, Jansen HM. Functional subsets of allergen-reactive human $\mathrm{CD} 4^{+} \mathrm{T}$ cells. Immunol Today $1991 ; 12: 392-5$.

3 Grewe M, Gyufko K, Schopf E, Krutmann J. Lesional expression of interferon- $\gamma$ in atopic eczema. Lancet 1994; 343:25-6.

4 Grewe M, Walther S, Gyufko K, Czech W, Schopf E, Krutmann J. Analysis of the cytokine pattern expressed in situ in inhalant allergen patch test reactions of atopic dermatitis patients. $\mathbf{J}$ Invest Dermatol 1995; 105:407-10.

5 Hamid Q, Boguniewicz M, Leung DYM. Differential in situ cytokine gene expression in acute vs. chronic atopic dermatitis. J Clin Invest 1994; 94:870-6.

6 Yamada N, Wakugawa M, Kuwata S, Yoshida T, Nakagawa H. Chronologic analysis of in situ cytokine expression in mite allergeninduced dermatitis in atopic subjects. J Allergy Clin Immunol 1995; 96:1069-75.

7 Thepen T, Langeveld-Wildschut EG, Bihari IC et al. Biphasic response against aeroallergen in atopic dermatitis showing a switch from an initial $\mathrm{TH} 2$ response to a $\mathrm{TH} 1$ response in situ: an immunocytochemical study. J Allergy Clin Immunol 1996; 97:828-37.

8 Larsen FS, Diepgen T, Svensson A. The occurrence of atopic dermatitis in North Europe: an international questionnaire study. J Am Acad Dermatol 1996; 34:760-4.

9 Leung DY. Atopic dermatitis: new insights and opportunities for therapeutic intervention. J Allergy Clin Immunol 2000; 105:860-76.

10 Simons FE. Prospective, long-term safety evaluation of the H1receptor antagonist cetirizine in very young children with atopic dermatitis, ETAC Study Group: early treatment of the atopic child. J Allergy Clin Immunol 1999; 104:433-40.

11 Klein PA, Clark RA. An evidence-based review of the efficacy of antihistamines in relieving pruritus in atopic dermatitis. Arch Dermatol 1999; 135:1522-5.

12 Geba GP, Ptak W, Askenase PW. Topical tacrolimus and cyclosporine A differentially inhibit early and late effector phases of cutaneous delayed-type and immunoglobulin E hypersensitivity. Immunology 2001; 135:235-42.

13 Salek MS, Finlay AY, Luscombe DK et al. Cyclosporine greatly improves the quality of life of adults with severe atopic dermatitis: a randomized, double blind, placebo-controlled trial. $\mathrm{Br} \mathbf{J}$ Dermatol 1993; 129:422-30.

14 Camp RD, Reitamo S, Friedmann PS, Ho V, Heule F. Cyclosporine $\mathrm{A}$ in severe, therapy-resistant atopic dermatitis: report of an international workshop, April 1993. Br J Dermatol 1993; 129:217-20.

15 Gianni LM, Sulli MM. Topical tacrolimus in the treatment of atopic dermatitis. Ann Pharmacother 2001; 35:943-6.

16 Rajka G, Langeland T. Grading of the severity of atopic dermatitis. Acta Derm Venereol (Suppl. Stockh) 1989; 144:13-4.

17 Aoyama H, Tabata N, Tanaka M, Uesugi Y, Tagami K. Successful treatment of resistant facial lesions of atopic dermatitis with $0.1 \%$ FK506 ointment (letter). Br J Dermatol 1995; 133:494-6.

18 Severity scoring of atopic dermatitis: the SCORAD Index. Consensus report of the European Task Force on atopic dermatitis. Dermatology 1993; 86:23-31.

19 Matthews JN, Altman DG, Campbell MJ, Royston P. Analysis of serial measurements in medical research. Br Med J 1990; 300:230-5.

20 Tofte SJ, Hanifin JM. Current management and therapy of atopic dermatitis. J Am Acad Dermatol 2001; 44 (1 Suppl.): S13-6.

21 Leung DY, Soter NA. Cellular and immunologic mechanisms in atopic dermatitis. J Am Acad Dermatol 2001; 44 (1 Suppl.):S1-12.

22 Bornhovd E, Burgdorf WH, Wollenberg A. Macrolactam immunomodulators for topical treatment of inflammatory skin diseases. J Am Acad Dermatol 2001; 45:736-43. 
23 Hanifin JM, Chan S. Biochemical and immunologic mechanisms in atopic dermatitis: new targets for emerging therapies. J Am Acad Dermatol 1999; 41:72-7.

24 Ruzicka T, Assmann T, Homey B. Tacrolimus: the drug for the turn of the millennium? Arch Dermatol 1999; 135:574-80.

Mrowietz U. Macrolide immunosuppressants. Eur J Dermatol 1999; 9:346-51.
25 Wollenberg A, Bieber T. FK-506/Tacrolimus. In: Burg G, Dummer RG, eds. Strategies for immunointerventions in dermatology.

Berlin: Springer, 1997; 53-7.

26 Reitamo S, Rissanen J, Remitz A et al. Tacrolimus ointment does not affect collagen synthesis: results of a single-center randomized trial. J Invest Dermatol 1998; 111:396-8. 